\title{
Semiotic Analysis of Gender Constructions among Facebook Users in Kenya
}

\author{
${ }^{1}$ Gerald Otieno Njura, ${ }^{1 *}$ Dr. Erick Omondi Odero, ${ }^{2}$ Dr. Pamela Anyango Oloo \\ ${ }^{1}$ Department of Languages, Linguistics and Literature, Rongo University, Kenya \\ ${ }^{2}$ Department of Linguistics, Maseno University, Kenya \\ *Corresponding Author: geraldnjura@gmail.com
}

\begin{abstract}
This study aimed at examining how male and female identities are constructed using visual images posted in particular Facebook Groups frequented by Kenyans. To this end, the theory of Visual Social Semiotics by Kress and van Leeuwen (1996; 2006) was employed in the interpretation of data. A descriptive qualitative approach was employed where particular features of the images were identified, described and interpreted. A total of six images were purposively selected from five Facebook Groups and a content analysis, with a checklist used to identify relevant features for analysis. The study found out that there is a major change in the identities of both males and females. Even though there was a desire by men to retain their dominant position, the images showed a shift from the traditional muscular, strong, powerful and macho male towards a vulnerable, weak and prone-to-criminal acts man. Female's identities have also changed from the traditional one, who was always associated with the kitchen, child birth towards a more assertive, powerful and professional identity. As a result, the study recommends that the Kenyan society ought to take a more serious look into the welfare of the boy-child as it appears that the boy child has been left behind by a more-empowered Kenyan girl.
\end{abstract}

Key words: Semiotic, Images, Visual, Gender, Identities

\section{Introduction}

The concept of semiotics has been defined differently by different scholars. Generally speaking, semiotics is the study of signs. Hall $(1997$, p. 6) defines semiotics as 'the study of signs and their role as tools of meaning making in culture.' Every sign is composed of a signifier, a structure that can be observed and a signified, the meaning that particular structure has in particular cultural context (van Leeuwen, 2005). Van Leeuwen (2005) and Kress (2010) developed analysis of signs further and called their approach social semiotics where the term 'resources' was used instead of signs. Semiotic resources include language, images, gestures, sound, etc. (Kress, 2010). The concern of social semiotics is the underlying available repertoire of signs and their use in context to communicate wider ideas, moods, attitudes and identities' (Machin \& Mayr, 2012).
Gender refers to the social roles that men and women play in particular societies. Underlying these roles is the existence of power relations between men and women. Some people consider gender as not synonymous with the biological sex and that it is shaped by culture, social relations and natural environment. As a social construct, gender develops through the interactions of numerous social factors, including all individuals and social encounters. Goffman (1976) posits that gender is a sociallyshared concept that is developed within individuals through socialization and it is correlated with the biological sex. It is materialized through social institutions such as media (print, electronic and social), sports and academia. These social institutions represent gender in ways that can be both stereotypical and reconstructive, that is, they can spread and reaffirm the already held views about gender roles and relations, but they can also 
represent gender in a way that challenges the status quo.

This study selected Facebook as one of the modern social institutions and platforms where participants do and display gender, sometimes consciously and sometimes unconsciously. The study sought to interpret gender notions that are promoted through images posted on Facebook in specific Facebook Groups that had huge followings in Kenya. These Facebook images not only endorse socially constructed gender beliefs but they also make readers accept or question whatever content is posted in these Facebook Groups.

\section{Literature Review}

Critical studies of language hold that every communicative practice, whether it is done in language or in images, is ideological in nature and the goal of critical analysis is to attempt to reveal those ideologies and provide the audience with critical awareness (Fairclough, 2013). This section presents a review of studies in critical linguistics in the area of gender and gender constructions in various media platforms.

\section{Gender Constructions in the Media}

Gender is a social construct that refers to the roles played by men and women and the power relations involved in the implementation of these roles. These roles and power relations are taught to the young ones by various socializing institutions like family, school, church and the community in which one is born and raised. Language is the key instrument in this socialization even though images (visual communication) equally play an important role in the socialization of community members into their gender and gender roles. Thiel (2005) observes that 'males and females perform what they interpret their gender to be based upon; what culture has taught them to be the correct interpretation of their gender.' This means that even though one is free to display whatever identity one prefers in either faceto-face or virtual communication, men and women still tend to display attributes and traits thought to be sought by others including the opposite sex (Albright, 2001).

Gender role is never static, it evolves. Doane (2003) indicates that in the 1980s, masculinity was characterized by activeness. Men were frequently captured in active roles than women, who were often put in display in front of the male gaze. This active identity of the man was shown to diminish in the 1990s where a sexualized image of the man was the core desire. During this period, men were shown as attractive and muscular, symbolizing their desire for power and dominance (Dyer, 1992). Women, on the other hand still retained their identity of passivity and were sexualized, that is, their sexual appeal was emphasized in the representations. Women were shown skimpily dressed and their postures were sexually suggestive.

Several studies, including Lovesque and Lowe (1999) have indicated that compared to women, men's photos displayed in the media tend to focus on their face rather than their body, as is in the case of women. This trend was found to resemble the situation in America, Canada, Austarlia and Norway when analyses of online representations of male politicians were done (Konrath \& Schwarz, 2007). With regards to facial expressions, studies indicate that women tend to use gaze more frequently than men (Larsen \& Schakelford, 1996). This means that male images display men as objects to be looked at as they show a complete disinterest on the viewers. Men are also more frequently represented in public spheres. Other studies such as Fowles (1996) have indicated that in most advertisements, men are usually depicted somewhere outdoors, or in business settings, in sporting activities, in restaurants and bars and less likely at home. Women on the other hand are likely to be depicted somewhere within the home, either in the kitchen, nursing the baby, doing some cleaning work or in the company of a male companion when depicted outside.

There is not much studies in Kenya aimed at analyzing the visual representation of gender identities with the exception of Mokamba- Kimuna's (2003) study on gender stereotyping as shown in Kenyan television commercials. This particular study reported that Kenyan advertisers use the woman's sexuality to sell various products. Here the female gender is commoditized as a product for sale.

This study analyzed the representation of gender on Facebook. Facebook, since its emergence, has attracted the attention of adolescents and young adults. This is so because Facebook offers users an outlet for their desire to communicate (Ross, Orr, Sisic, Arseneault, Simmering \& Orr, 2009), influences the exploration and formation of personal and social identity (Shapiro, \& Margolin, 2014), allow users to construct an online identity by strategically choosing what to disclose to their audience and how to make 
these disclosures (Walther, 2007), while at the same time affording them with the opportunity to participate in social comparison and express aspects of the ideal-self (Manago, Graham, Greenfield, \& Salimkhan, 2008). Facebook is of interest to these adolescents and young adults as it allows them to experiment with different selves in a process of creating the desired self (Zhao, Grasmuck, \& Martin, 2008), or creating who they think they should be according to social norms (Back, Stopfer, Vazire, Gaddis, Schmukle, \& Egloff, 2010). Research has revealed that even though Facebook offers many benefits, it also has a dark side in that it can be a source of relational and psychological issues that can be detrimental to both personal and professional life of the user (Brooks, 2015).

Gender is a dynamic phenomenon that depends on many factors. The existing body of literature show a general bias in the analysis of gender that tend to favor traditional media such as newspapers, television, school books etc. This study focused on a new media, Facebook with the goal of assessing gender construction by use of images posted ion Facebook.

\section{Theoretical Framework}

This study employed the theory of Visual Social Semiotics by Kress and van Leeuwen $(1996 ; 2006)$ as its theoretical framework to investigate gender construction in Facebook discourses. Visual social semiotics follow Halliday's theory of metafucntions (Halliday \& Mathiessen, 2004) which postulates that language fulfils three metafunctions simultaneously: ideational, interpersonal and textual. The same functions have been extended to visual social semiotic resources by Kress and Van Leeuwen (1996; 2006) and renamed as representational (for ideational), interactive (for interpersonal), and compositional (for textual).

Representational metafunction deals with the way our experience(s) is/ are encoded visually. This metafunction is achieved either by narratives and/or conceptual structures (Kress \& van Leeuwen, 1996). Compositional metafunction refers to the 'way in which representations and communicative acts cohere into the kind of meaningful whole called "text" (Kress \& van Leeuwen, 1996 p. 181).

The above two metafunctions were not the focus of this study but the below function was. The interactive metafunction is represented by the patterns of interactions between participants. In any visual text, there are many types of participants that are involved, namely, represented (depicted) participants and interactive (real) participants. Depicted participants are the people or objects shown in an image. In the case of this study, these are the images of men and women. Interactive participants are the viewers of these visual texts. This study dealt with the kind of interaction that exists between the depicted participants and the interactive participants. The depiction of these represented participants can lead to various relations within the same types and between the different types (Kress \& van Leeuwen, 2006 p. 114). The interactive meaning of an image can be analyzed from three different dimensions (Kress \& van Leeuwen, 1996): image act, social distance, social relation.

\section{The Image Act}

The image act is related to the gaze direction of the represented participant(s), which can be directed at the viewer (demand image) or away from the viewer (offer image). According to Kress and van Leeuwen (1996), demand images are considered to establish an imaginary relation with the viewer since they address the viewer directly. The kind of relationship established between the image and the viewer depends on other features of the image such as facial expressions and gestures (Machin \& Mayr, 2012). For instance, a demand image emphasized by a smile invites the viewer to enter into a relation of social affinity and identification with the viewer (Kress \& van Leeuwen, 2006). Offer images, on the other hand, address the viewer indirectly, as there is no contact created between the depicted and interactive participants. These kinds of images depict the represented participants impersonally as items of information or objects for contemplation (Kress \& van Leeuwen, 2006 p. 119). By analyzing image acts, this study intended to reveal whether the images of men and women suggest engagement or detachment between the participants.

\section{Social Distance}

In images, as in real life, distance communicates interpersonal relationships. We stay away from strangers and we stay close to our nearest and dearest. Distance indicates the closeness of our relationships. In images, distance, according to Kress and van Leeuwen (1996), is indicated by different sizes of frame, namely: close-up, medium-shot and long-shot. In close-up, the image shows the head and shoulders of the represented participant while 
in very close-shot, the represented participant is shown anything less than the head and shoulder (Kress \& van Leeuwen, 1996). This distance indicates a close social circumstance where participants are captured in an informal relation typical between friends, family and acquaintances. In medium-shot, the represented participant can be shown anywhere from full body to waist upwards. The medium closeshot cuts off the subject approximately at the waist, the medium-shot approximately at the knees while the medium-long shot shows the full body. This is the distance where business and social interaction is conducted. It indicates an impersonal relationship. In the long-shot the human figure occupies about half the height of the frame and the very long shot is anything wider than that. This is the distance between people who are strangers and remain strangers to one another (Kress \& van Leeuwen, 1996). In this study social distance was analyzed with the aim of revealing the representation of men and women in terms of how they are represented as close or far to and from the viewers.

\section{Social Relation}

Social relation refers to the angle from which we see the represented participant(s). This includes the vertical angle, which defines whether we see the represented participants from above, eye level or from below and the horizontal angle, which defines whether we see a person frontally or from the side or perhaps from somewhere in between. Vertical angle symbolizes power while horizontal angle symbolizes involvement or detachment (Van Leeuwen, 2005). Kress and van Leeuwen (2006) interpret vertical angle as related to power differences. To look down on someone is to exert imaginary symbolic power over the person; to look up at someone signifies that the person has symbolic power over the viewer, whether as an authority, a role model or older. To look at someone from eye level signals equality. Van Leeuwen (2005) states that horizontal angle realizes symbolic involvement or detachment. Involvement is symbolized by frontal angle while detachment is signaled by side-angle.

In this analysis, social relation was analyzed to decipher the representation of both men and women along the horizontal and vertical angles with the goal of revealing whether either gender is depicted as having or lacking power and if either gender is captured as involved with or detached from the viewer.

\section{Methodology of the Study}

This section outlines the methodology used in conducting the study. It highlights the study design, approach, population and sampling, data collection procedure and analysis.

\section{Research Design}

This study employed a descriptive qualitative research design as this study focused on description, analysis and explanation of features of images downloaded from Facebook Groups' pages with the goal of revealing observed identities projected. The research approach used was qualitative as it follows descriptive and explanatory qualitative procedures and analyzes and interprets the data on the basis of the features drawn from Kress and van Leeuwen's (2006) theory 'Reading Images: The grammar of Visual Design'. Qualitative research encompasses various approaches such as discourse analysis, grounded theory, ethnography, semiotics and critical discourse analysis (Pelkinghorne, 1983). Through a semiotics approach, the study provides insights into the gender relations debate in Kenya by revealing the changing roles in the gender equity and equality debate.

\section{Population and Sampling}

The targeted population comprised all the images of men and women and any other object/ objects used to represent men or women, posted on five Facebook Groups' Pages.

A non-probability purposive sampling technique was used in this study. A total of 6 images were selected for analysis on the representation of gender through a qualitative analysis. The six images were purposively selected based on criteria that: the image had to be found in the sampled Facebook groups; images of males or females; posted between the period January, 2017 and May, 2019; and the image had to be rich in the features outlined by the theory, as assessed by the checklist prepared by the researcher.

\section{Data Collection}

Data for this study includes images that were posted in five popular Facebook Groups with huge membership and following in Kenya. The data were downloaded from these Group pages where the author is a member. The Groups are Buyer Beware, Nyakundi is Cyprian, Save the Boychild, Boy Child (Kenya), and Kenya Boy Child. The Facebook Groups were purposively selected based on their content for discussion which frequently touched on men and 
women relationships and relations in Kenya. The images were searched, and saved in a folder in the researcher's laptop ready for scrutiny. A content analysis aided with a checklist, prepared from the theoretical tenets, were used to identify relevant features for analysis.

\section{Consent Acquisition}

McEnery and Hardie (2012, p.59) discussing ethical concerns surrounding gathering data from the internet suggest three ways of addressing copyright issues. First, they put it that, researchers could contact copyright holders and request permission to use the data. This was not done as it proved challenging identifying the copyright holders of these images. Second, McEnery and Hardie, posit that data can as well be collected from websites that allow the reuse of texts. Third and finally, they assert that one can also collect data without seeking permission as there is no need to request permission to use information that is already in the public domain. Townsend and Wallace (2016) support this position by asserting that social media users have agreed to the terms and conditions of the platform, many of which include clauses on access and re-use of data by third party. As such no consent was sought for use of the images in this study as they are already available in a public platform. Despite this, the sources from where the images were taken were adequately cited.

\section{Findings and Discussion}

This section explains some important methodological and theoretical steps which were included to analyze and interpret data. It provides the interpretation of the collected data in the light of theoretical principles drawn from the visual social semiotic theory.

\section{Analysis of Image Act}

Image 1 is used as the profile picture of a Facebook Group Page 'Save the Boy Child Campaign'. The profile description of the page reads, 'in this campaign, we want to save the boy child from becoming a wife beater, rapist and stalker.

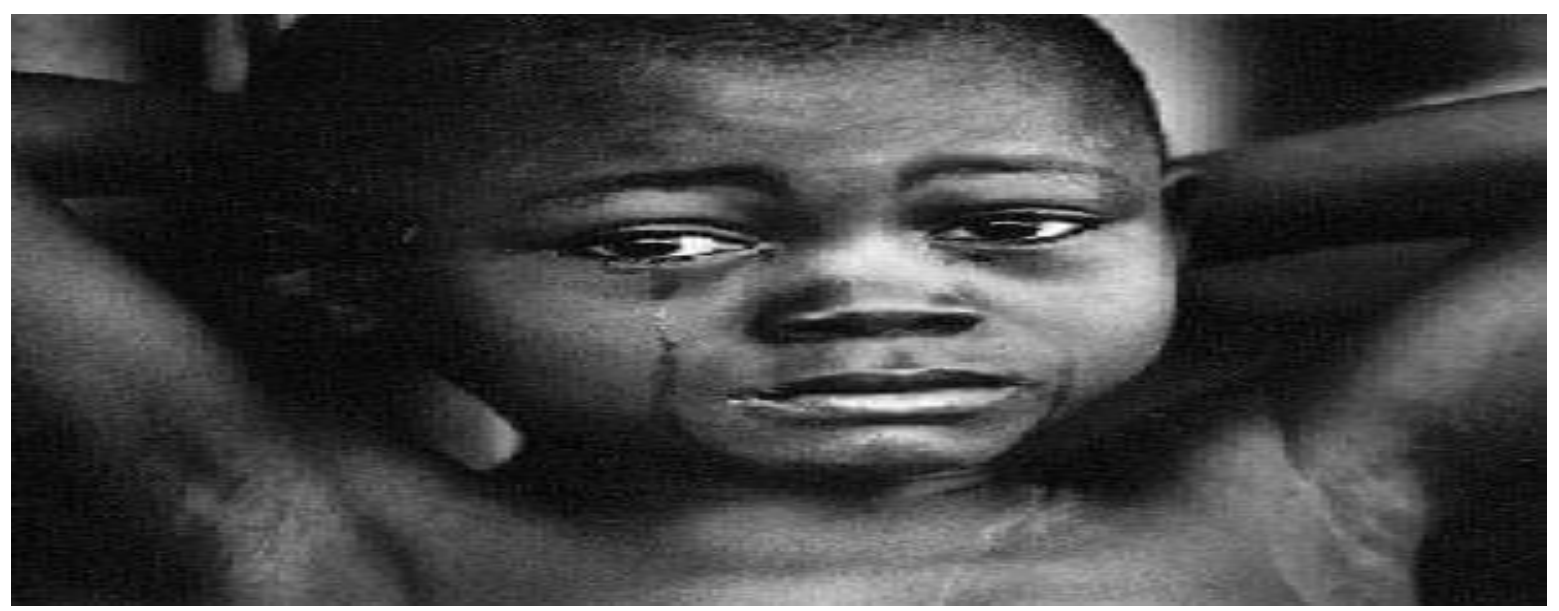

Image 1: An image of a boy used as the Profile picture of 'Save the Boy Child Campaign' (2018)

Analysis of image act was done through the interpretation of gaze direction of the represented participants. In the image 1 , the gaze is directed at the viewer and this kind of gaze is known as demand (van Leeuwen, 2005), so this is a demand image. Van Leeuwen (2005) further states that when people are captured looking at us, they address us directly with their look, they articulate a kind of visual 'you', a symbolic demand. This kind of image demands something from us the viewers, and what that something is, in this case, is signified by the linguistic elements accompanying the image, facial expressions, gestures and angle of the image. From the linguistic elements accompanying the text, the study derives the fact that this image of a boy child demands from us, the viewers, to be rescued from his perceived identity as a wife beater, a rapist and a stalker. All these are vices that unfortunately are the current identities of the male gender in Kenya. The study argues that the Kenyan man is stuck in his perceived negative identity and wishes to transform into an acceptable member of the society.

The facial expression denotes and connotes sadness, tears streaming down the cheeks; the gesture is that of hopelessness and desperation, hands folded behind the head; the angle is frontal, eye-level symbolizing demand for equality, fairness and better treatment as an equal member of the society. 
The analysis of the image act of the boy's image suggests that the projected identity of Kenyan men is that of a hopeless, desperate, stuck man in his societal perceived identity as a wife batterer, rapist and stalker. $\mathrm{He}$ is calling for help from the stakeholders; the family, government, church and the non-government organizations.

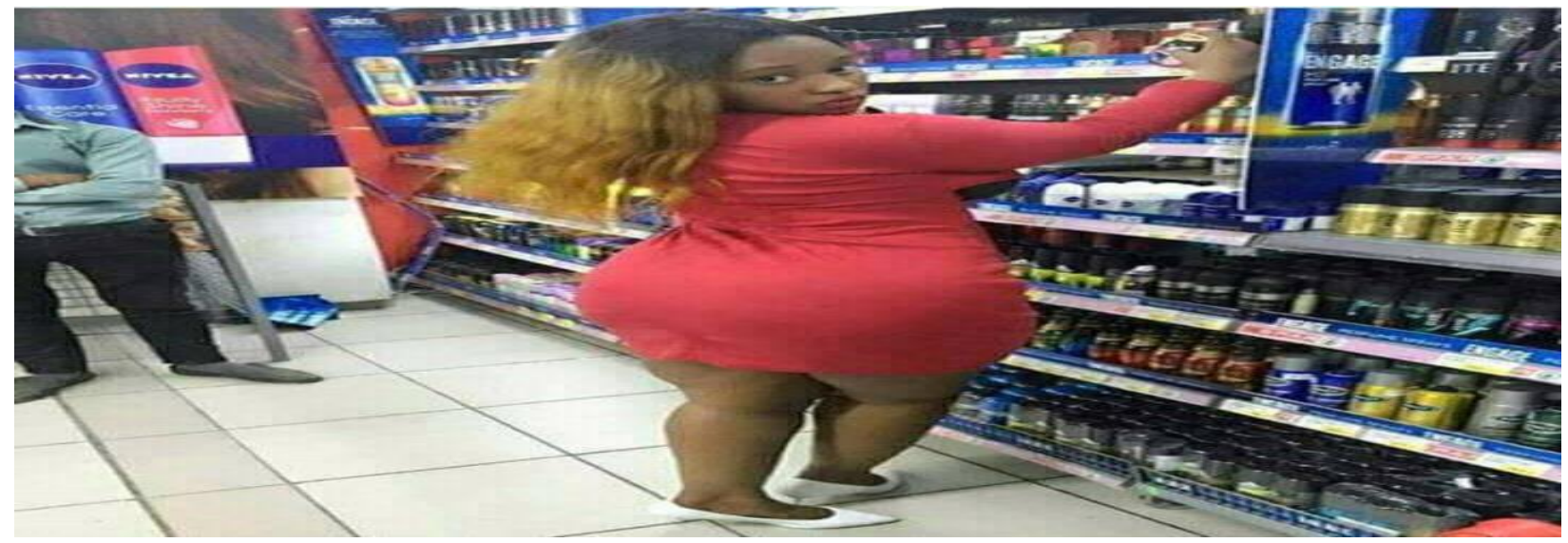

Image 2: A lady shopper, Taken from Cyprian is Nyakundi Group (2019)

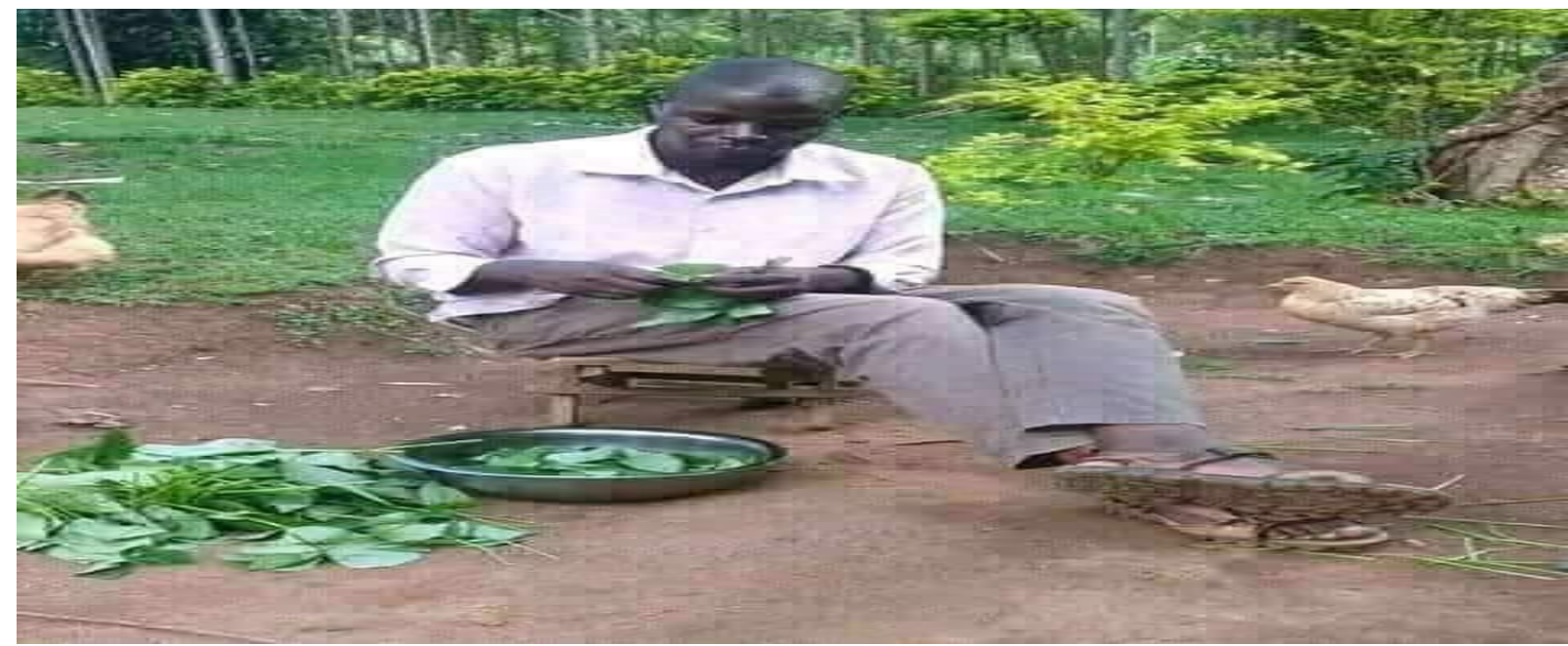

Image 3: A man sorting vegetable, The Boy Child in Kenya (2018)

In image 2, a woman is shown within a supermarket, probably shopping. There is a man, partially shown standing by, supposedly, a supermarket attendant. The viewers cannot see the face of the man. The woman's body is facing away from the viewers, but with the head turned towards the camera, we can see her face and facial expressions. Image 2 is also accompanied by the words 'utajua ni slayqueen akikulazimishia mahaga kama huyu hapa' (translated as: you will know she is a slay queen when she forces her hips on you like this one here). This image too, is a demand image; it creates contact and invites an interaction with the viewers. The kind of interaction demanded by the image is signaled by the linguistic elements accompanying the image, the body language, facial expression and angle. A combined reading of the text and the body language suggest that the reader is invited to focus his/her attention on the enlarged hips of the woman, the red, short dress, the crossed legs, the white pair of shoes and long hair. The woman is depicted as seeking attention and being a woman, the study infers that she is seeking for male attention through her sexy dress code and sexy body.

\section{Social Distance}

Machin and Mayr (2012) explain that in images, just like in real life, distance signifies social relations. We 'keep our distance' from people we do not want to be in touch with and 'get close' to people we see as our circle of friends, acquaintances or intimates. This study used two images to interpret the representations of men and women via social distancing.

Image 3 was accompanied by the text 'where did the boy child go wrong? How comes men today are 
working in the kitchen?' The image shows a man seated sorting vegetable. He is shown facing the viewers but not keeping eye contact, his concentration is on the vegetables he is sorting. This is a medium-long-shot image where the full body of the represented participant is shown. This image is meant to take us close to the 'real' status of this man and men generally, which is reflected in the discourse in the accompanying text. The sitting posture, leg-crossing, is not a masculine posture adding to the argument that this image intends to bring us closer to the suffering of this man. His facial expression communicates sadness as well. The study therefore derives the fact that this image, together with the accompanying text construct men as oppressed and sad lot who has been reduced to performing what traditionally were feminine roles.

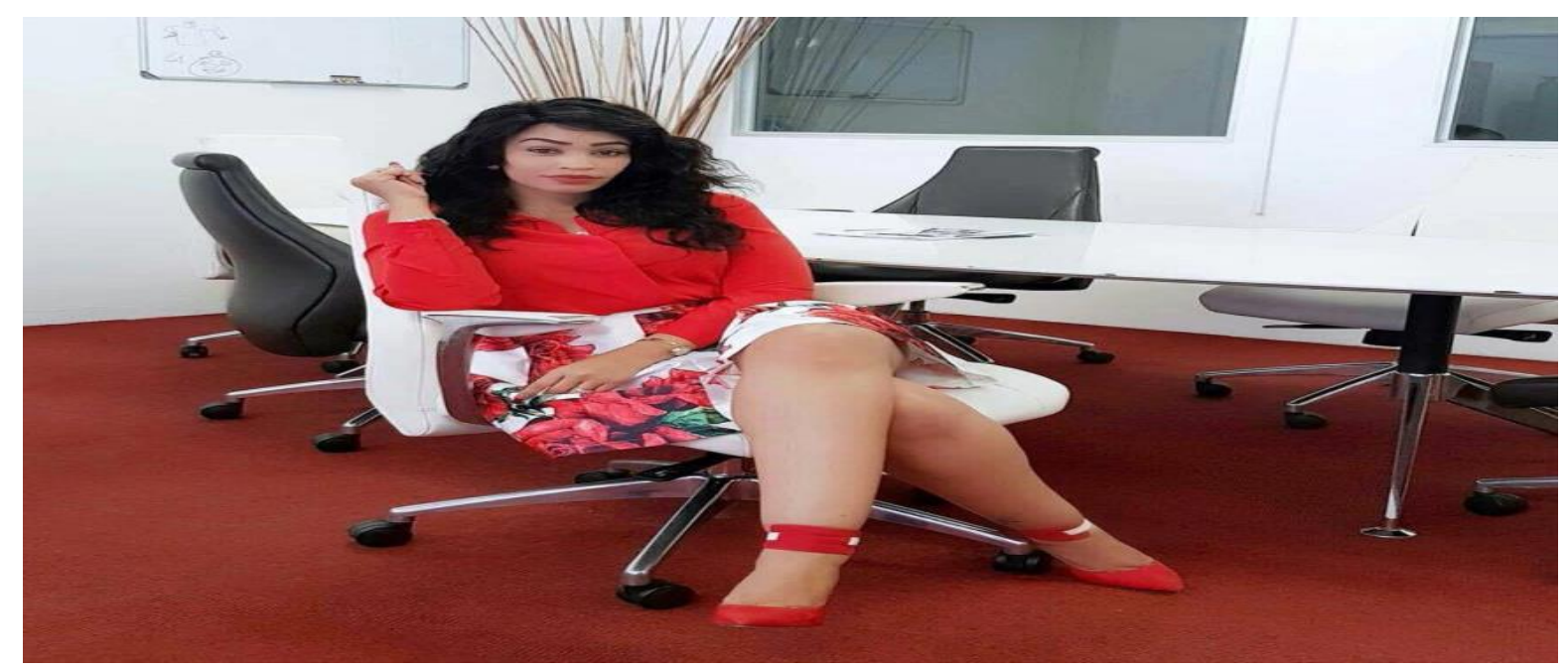

Image 4: A woman in an office, Cyprian is Nyakundi (2018)

Image 4 is of a popular media personality, business lady and socialite, Zari Hassan. The image depicts her in medium long shot as viewers can see her whole body. She is sat in what appears like a boardroom, well furnished with a floor carpet and expensive furniture. The image depicts her in elegant dress code with matching make-up including long hair. Her leg crossing posture is not only feminine but sexy as well. The choice of the medium long shot is meant to give viewers full access of her expensive office and lifestyle. We are invited to admire her as she takes a confident pose. This portrayal constructs a new image of women as belonging to the boardroom which was traditionally a preserve for men. Her grooming generally and dress code specifically reinforces her feminine gender, but also asserts her authority. Machin and Mayr (2012) conclude that 'medium shots are used where it is important that we see what the woman is wearing and to connote her acting in modernist settings. This succinctly captures image 4 , as it shows the woman as a modern one as opposed to the traditional woman whose place was commonly around home.

\section{Social Relation}

In visual communication, social relation is captured by angle. There is both the horizontal and vertical angle (van Leeuwen, 2005). In horizontal angle, represented participants may be shown face to face with the viewers indicating involvement, viewers may watch him/her from the sides, which connotate detachment and participants may also be depicted from behind, which serves to offer us their point of view (Machin \& Mayr, 2012). On the vertical angle, participants may be portrayed above, at eye level or below the viewers.

Image 5 depicts a group of boys smoking. The viewers confront them, yet they look slightly to the side. Combined with the closeness, the image appears intimate to a degree, yet they are depicted as slightly to the side, so we are not directly involved-we are observing them. We are observing them engage in a vice and probably criminal act, if what they are smoking is illegal according to the national laws. The close-shot together with the horizontal angle of the image bring viewers closer to the life of these young boys. Their grooming portrays an unkempt state with uncombed hair, dirty-looking clothes and their curiosity and concentration on the cigar depict them as hopeless, jobless and poor individuals. This depiction of Kenyan boys as vulnerable to drug use is supported by studies such as Chan'gach (2012). 


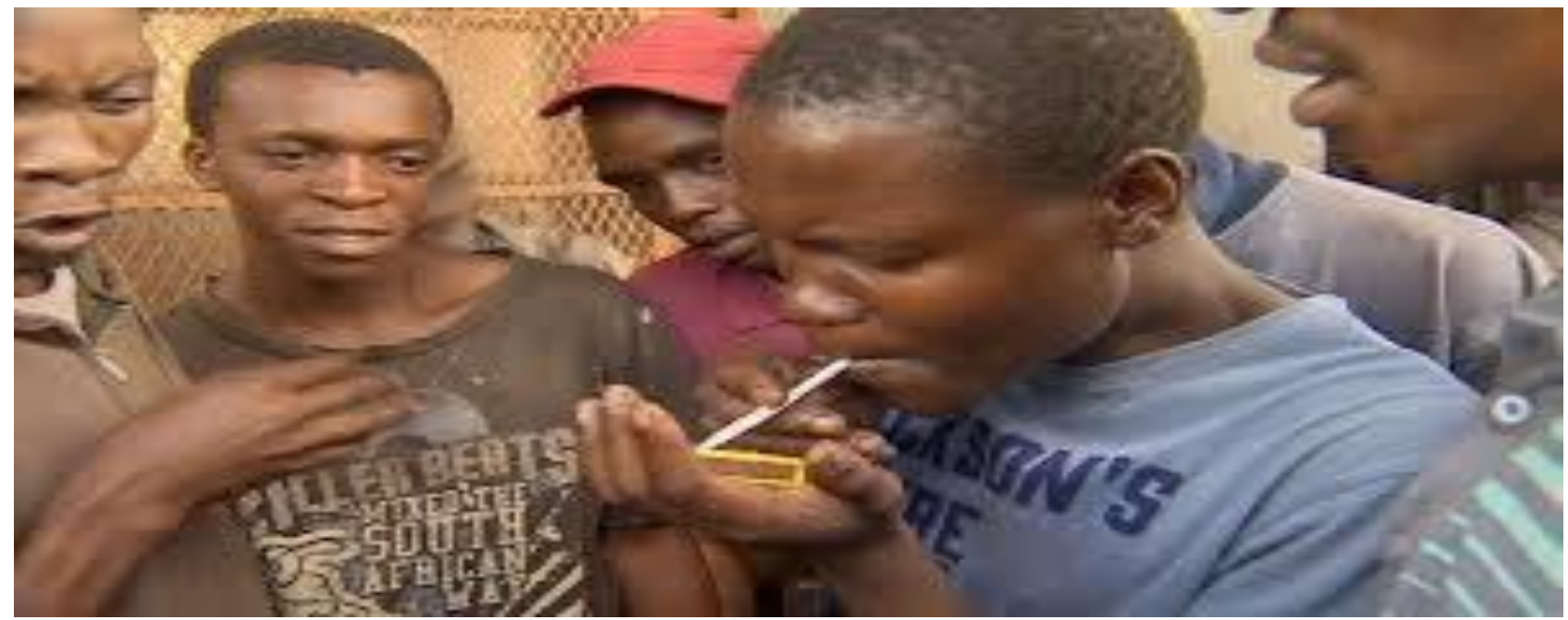

Image 5: A group of men shown smoking, Buyer Beware (2019)

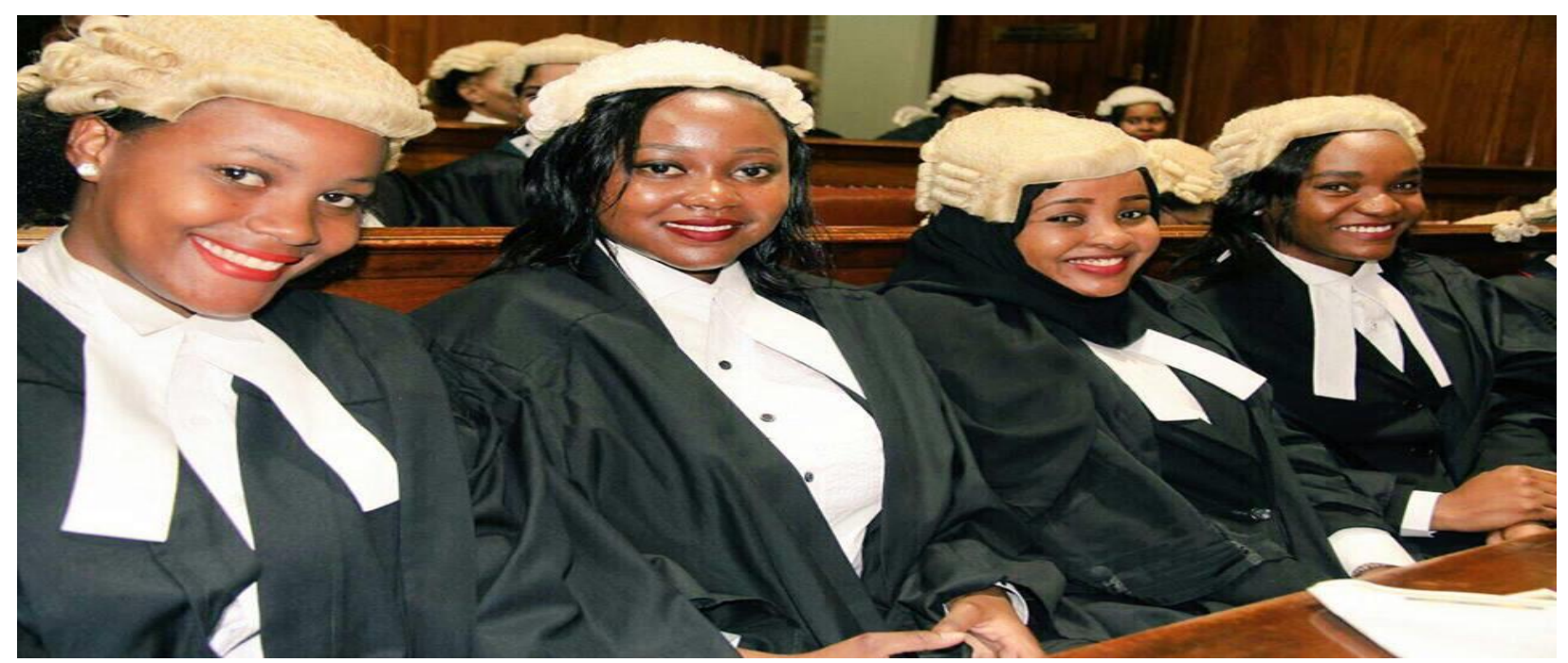

Image 6: A Group of female lawyers in a courtroom, Kenya Boy Child (2018)

Image 6 shows a group of lawyers in a courtroom. In the front row are four women who are captured as a medium close shot. On the vertical angle, they are shown at eye level with the viewers depicting them as having equal status with the viewers. On the horizontal angle, they are face to face with the viewers depicting them as involved with the viewers. A combined reading of angle, camera shot (close medium), facial expression (smiling), and eye contact with the viewers construct them as very involved. The image suggests that these are people to be admired and emulated as opposed to the information suggested in image 5 .

\section{Conclusions and Recommendations}

This part presents the conclusions and recommendations of the study.

\section{Conclusions}

The analysis of the semiotic construction of gender identities in Facebook discourses demonstrate that gender is indeed dynamic. The study concludes that the traditional portrayal of men as powerful, strong, and professionals has changed. The Kenyan men are now depicted as weak, engaging in household chores, and are vulnerable to criminal activities. They are also portrayed as detached from the mainstream society contrary to their previous identify of being the family head and by extension the society's leader. Women, on the other hand, have changed from being the family keepers, child bearers, and cooks to become confident professionals and property owners. However, despite their success at school and in work places, women are still portrayed as proud of their femininity and their sexy identities.

\section{Recommendations}

The analysis of data points to a feeling by the Facebook users that the male members of the Kenyan society are generally neglected. The study therefore recommends that families, schools, 
churches, government and the non-government organizations should take a keener interest in the development of the boy child, just as they did with the girl child. The society is more balanced when both genders get their equal share of attention.

\section{Reference}

Albright, J. M. (2001). Impression formation and attraction in computer-mediated communication. (Unpublished Doctoral Dissertation), University of Southern California.

Back, M. D., Stopfer, J. M., Vazire, S., Gaddis, S., Schmukle, S. C., Egloff, B., \& Gosling, S. D. (2010). Facebook profiles reflect actual personality, not selfidealization. Psychological science, 21(3), 372-374.

Brooks, S. (2015). Does personal social media usage affect efficiency and well-being?. Computers in Human Behavior, 46, 26-37.

Chang'ach, J. K. (2012). An Unfinished Agenda: Why is the Boy-Child ndangered? International Journal of Academic Research in Business and Social Sciences, 2(4), 181.

Doane, M. A. (2003). The close-up: scale and detail in the cinema. Differences: A Journal of Feminist Cultural Studies, 14(3), 89-111.

Dyer, Richard (1992) 'Don't Look Now: The Instabilities of Male Pin-up', in Richard Dyer (ed.). Only Entertainment, pp 103119. London \& New York: Routledge.

Fairclough, N. (2013). Critical discourse analysis: The critical study of language. New York: Routledge.

Fowles, J. (1996). Advertising and popular culture. Thousand Oaks, CA: Sage.

Goffman, E. (1976). Gender display. In Gender advertisements (pp. 1-9). Palgrave, London.

Hall, S. (Ed.). (1997). Representation: Cultural representations and signifying practices (Vol. 2). Open University: Sage Publications.
Halliday, M. A. K. (1994). Spoken and written modes of meaning. Media texts: Authors and readers, 7, 51-73.

Halliday, M. A.K. and Matthiessen, C. M. I. (2004). An introduction to functional grammar. $3^{\text {rd }}$ Ed. Hodder Education: London.

Konrath, S. H., \& Schwarz, N. (2007). Do male politicians have big heads? Face-ism in online self-representations of politicians. Media Psychology, 10(3), 436448.

Kress, G. R. (2010). Multimodality: A social semiotic approach to contemporary communication. London/ New York: Routledge.

Kress, G. R., \& Van Leeuwen, T. (1996). Reading images: The grammar of visual design. London/ New York: Routledge.

Kress, G., \& Van Leeuwen, T. (2006). Visual interaction. In The discourse reader, $\left(2^{\text {nd }}\right.$ edition), edited by Adam Jarwoski, and Nikolas Coupland, 362-384. New York: Routledge.

Larsen, R. J., \& Shackelford, T. K. (1996). Gaze avoidance: Personality and social judgments of people who avoid direct face-to-face contact. Personality and individual differences, 21(6), 907- 917.

Levesque, M. J., \& Lowe, C. A. (1999). Face-ism as a determinant of interpersonal perceptions: The influence of context on facial prominence effects. Sex Roles, 41(3-4), 241259.

Machin, D., \& Mayr, A. (2012). Critical discourse studies: A Multimodal Approach. London: SAGE Publications Ltd.

Manago, A. M., Graham, M. B., Greenfield, P. M., \& Salimkhan, G. (2008). Self-presentation and gender on MySpace. Journal of Applied Developmental Psychology, 29(6), 446-458.

McEnery, T., \& Hardie, A. (2012). Statistics in corpus linguistics. Support website for corpus linguistics: Method, theory and practice. 
Mokamba-Kimuna, B. (2003). Sustained gender stereotyping as shown in Kenyan television commercials, possible effects on the image of women and the way forward (Doctoral dissertation, University of Nairobi).

Polkinghorne, D. (1983). Methodology for the human sciences: Systems of inquiry. Albany: State University of New York Press.

Ross, C., Orr, E. S., Sisic, M., Arseneault, J. M., Simmering, M. G., \& Orr, R. R. (2009). Personality and motivations associated with Facebook use.Computers in human behavior, 25(2), 578-586.

Shapiro, L. A. S., \& Margolin, G. (2014). Growing up wired: Social networking sites and adolescent psychosocial development. Clinical child and family psychology review, 17(1), 1-18.
Thiel, S. M. (2005). “"IM Me” Identity Construction and Gender Negotiation in the World of Adolescent Girls and Instant Messaging', in Sharon R. Mazzarella (ed.) Girl wide web. Girls, the Internet, and the negotiation of identity.

Van Leeuwen, T. (2005). Introducing social semiotics. London/ New York: Routledge.

Walther, J. B. (2007). Selective self-presentation in computer-mediated communication: Hyperpersonal dimensions of technology, language, and cognition. Computers in Human Behavior, 23(5), 2538- 2557.

Zhao, S., Grasmuck, S., \& Martin, J. (2008). Identity construction on Facebook: Digital empowerment in anchored relationships. Computers in human behavior, 24(5), 1816- 1836. 